\title{
Employee Retention: Take an Insurance Company as an Example
}

\author{
Dongxiao $\mathrm{Yue}^{1, *}$ \\ ${ }^{1}$ College of Architecture and Environment, Sichuan University, Chengdu, Sichuan Province, China, 610065 \\ *Corresponding author. Email: ydx8898@163.com
}

\begin{abstract}
With the increasingly fierce competition among enterprises, the company's demand for outstanding employees is also increasing. Because highly capable employees can greatly improve organizational performance, human resource management has become an important part of each company's competitive advantage. In order to improve the competitiveness of enterprises and obtain sustainable business development, it is very important for employers to try their best to retain outstanding employees and improve their work efficiency. The purpose of this article is to explore the satisfaction of employees with the Chinese insurance company and the reasons for their retention, and to provide suggestions to the company to improve employee retention. In order to achieve this goal, this article collects qualitative data by conducting semi-structured interviews with 10 employees of an insurance company. According to interviews, it is found that the main problems faced by insurance companies are low employee enthusiasm and low public recognition. The company needs to promote corporate culture, improve employee work efficiency and adjust salary structure to retain core employees.
\end{abstract}

\section{Keywords: Employee Retention, Human Resource, Insurance Company}

\section{INTRODUCTION}

In the era of knowledge civilization, more and more companies realize that the current competition is the competition of talents. A good company can retain core employees by providing a comfortable working environment, reasonable salary, broad development space or other aspects, so as to improve the company's organizational performance. Therefore, employee retention is extremely important for companies in almost all industries. According to the American behaviourist Edgar H. Schein's "complex person hypothesis": Whether a person is willing to contribute to the organization depends on the relationship between the status of the organization and the individual's motivational structure [9]. Once the company is unable to provide employees with satisfactory conditions, employees will form a tendency to leave, and even make a decision to leave.

The 2020 epidemic has made the issue of employee retention more prominent. According to the "2021 Work Trend Index Report" released by Microsoft on March 22, $2021,40 \%$ of the more than 30,000 respondents in 31 countries and regions around the world consider resigning this year. $54 \%$ of people think they are overworked, and 39\% said they feel exhausted from work. The reason is that nearly one-fifth of the interviewees believe that their employers do not care about the balance of the employees' work and life. During the epidemic, a large number of online meetings and non-working hours of information communication have caused employees' physical and mental exhaustion. It can be seen that only by resolving the conflicts between the company and the employees immediately can the company retain its core employees and have a broad space for development.

\section{LITERATURE REVIEW}

The high employee turnover rate is a common problem in many industries. Retaining core employees is one of the problems that the company currently needs to solve. Personal dissatisfaction itself is a major reason for an employee to leave the firm. This dissatisfaction can arise from various factors such as compensation, job security, job autonomy, relationship with the supervisor and other colleagues [5]. Because different people have different understandings of the proportion of power needs, belonging needs and achievement needs, the dissatisfaction of employees is very complicated [7]. When the employee's disappointment with the job 
reaches a certain level, they will make the decision to leave. Therefore, companies must take measures immediately to improve employee satisfaction to retain core employees.

In order to survive in the highly competitive global economy, management must develop strategies to attract key talent, develop talent, and retain talent. This requires careful formulation of human resources strategies and coordination of the efforts of senior managers, human resources and reward professionals to effectively meet this challenge [9]. There are many ways to achieve this goal. For example, effective communication between managers and employees plays a big role. In order for employees to understand their suitability, organizations must have a standardized communication process that links employees with correct information from employers [1]. In addition, the relationship between managers and employees is also very important. If the leadership demonstrated by the company is not responsible for the employees, their pride and satisfaction with the organization may decrease [2]. Employee training is also one of the key factors of employee retention, which is important for most industries. Once employees are confident and motivated to complete a task, they are more likely to devote themselves to their work, and the company therefore reduces the turnover rate [4]. Although there are many ways to improve employee satisfaction, managers need to distinguish between hygiene factors and motivation factors. Managers cannot over-satisfy hygiene factors, because they do not contribute much to the improvement of organizational performance. Instead, managers should pay more attention to motivational factors to improve employees, improve the enthusiasm and work enthusiasm of employees, thus helping enterprises to develop faster [3].

Through reviewing the relevant literature, the researcher found that current scholars have analysed a variety of factors within the enterprise, and there have been many studies on the internal factors of the enterprise. However, since enterprises cannot exist independently of society, it is necessary to consider enterprises and society as a whole system. There are few studies in this area at present. Therefore, while drawing the conclusion of the interview, the researcher focused on analysing employee retention from a systematic perspective, and provided suggestions for the company to improve employee retention and avoid future brain drain.

\section{METHODOLOGY}

\subsection{Research method}

The data collection method utilized in this study is the semi-structured interview method. This method is chosen not only because it has a clear theme, but also because the researcher can control the interview process and structure to a certain extent, and can control the rhythm and play a guiding role in the interview process. Interview is an uncertain process of communication between the two parties, which will continue to change with the content of the exchange. The interviewer will play a prompt role in the interview by writing an interview outline in advance according to the interview theme, and conduct face-to-face interviews with the interviewees. The actual interview content will be slightly modified according to the interviewee's answers, and the specific questions will be changed according to the depth of the interviewee's answer and the harmony of the interview atmosphere.

\subsection{Research Design}

The purpose of this research is to explore the reasons for the retention of employees of insurance companies. The interviewees were 4 department managers, 4 general staff and 2 salesmen.

American psychologist Abraham Maslow elaborated on Maslow's Hierarchy of Needs in his book "Incentive and Personality". He divided human needs into five levels: physiological needs, safety needs, social needs, respect needs, and self-actualization needs. In this interview, the researcher designed the interview outline from the five major needs based on Maslow's demand theory. The content of the interview was focused on ten aspects of company culture, departmental atmosphere, infrastructure, working hours, benefits, salary, training, promotion mechanism, colleague relationship, and superior-subordinate relationship. Through communication with ten employees, a preliminary conclusion of employee retention was reached. 


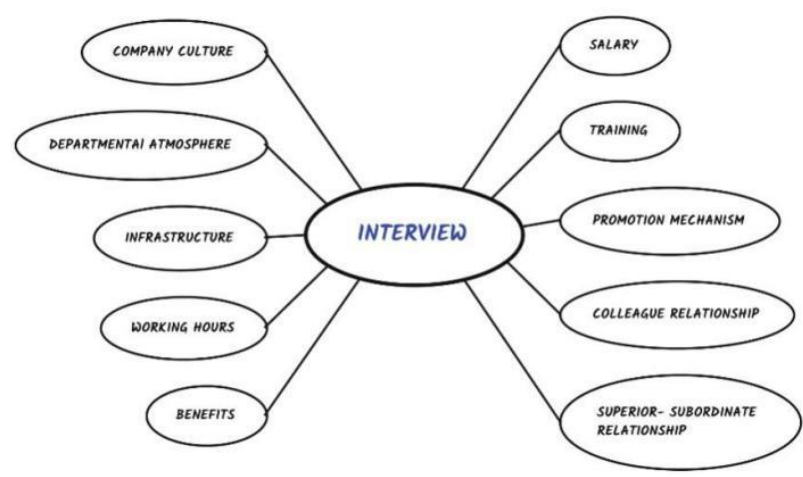

Figure 1 The content of the interview

This article will study the impact of employee retention on companies in various industries in the past ten years, as well as the measures and strategies that companies should adopt. This article only studies the employees of an insurance company.

\subsection{Research Questions}

The two research questions of this study were:

(1) What are the real reasons why employees stay in the company?

(2) Will the employee's satisfaction with the company affect the company's adjustment to the employee's future training plan?

\subsection{Research Objectives}

The overall goal of this article is to study the important factors that really affect employee retention in the insurance industry in China, and provide suggestions to the company to ensure employee retention and avoid future brain drain.

Specific goals:

(1) Evaluate employees' satisfaction with the Bei'an branch of China Life Insurance Company.

(2) Explore the impact of social environment and corporate culture on employee retention.

(3) Evaluate the impact of training and promotion space on the insurance company's employee retention rate.

(4) The purpose of this research is to explore the impact of the insurance company's employee relationship on employee retention.

(5) Assess the impact of the insurance company's salary and reward strategy on employee retention.

\section{RESULTS AND ANALYSIS}

Table 1. Interview Results

\begin{tabular}{|c|c|c|c|c|c|c|c|c|c|c|}
\hline & $\begin{array}{c}\text { Com pany } \\
\text { Culture }\end{array}$ & $\begin{array}{c}\text { Departm en tal } \\
\text { A tm o sphere }\end{array}$ & In frastructure & $\begin{array}{c}\text { W orking } \\
\text { Hours }\end{array}$ & Benefits & Salary & Train ing & $\begin{array}{c}\text { Prom o tion } \\
\text { M echan ism }\end{array}$ & $\begin{array}{c}\text { Colleague } \\
\text { Re lationsh ip }\end{array}$ & $\begin{array}{c}\text { Superior } \\
\text { subord inate } \\
\text { Re lationsh ip }\end{array}$ \\
\hline Satiffied & $20 \%$ & $30 \%$ & $100 \%$ & $10 \%$ & $100 \%$ & $20 \%$ & $90 \%$ & $80 \%$ & $90 \%$ & $100 \%$ \\
\hline D issatisfied & $80 \%$ & $70 \%$ & 0 & $90 \%$ & 0 & $80 \%$ & $10 \%$ & $20 \%$ & $10 \%$ & 0 \\
\hline
\end{tabular}

Through this interview, the researcher has the following findings regarding employee dissatisfaction:

First, the low social recognition of insurance companies has brought great obstacles to the work of employees. Because the people have a stereotype of insurance salespersons, they have a feeling of resistance and do not cooperate with salespersons, resulting in a low sense of accomplishment for field employees at work. 8 out of 10 interviewees said that the social recognition of the insurance job is low, and this is the biggest obstacle.

Second, the working atmosphere of insurance companies still needs to be improved. Because young people generally have no interest in insurance work, the staff structure of insurance companies is seriously aging, and the work enthusiasm of employees is not as high as in other industries. 7 of the 10 interviewees said that many employees were not enthusiastic, which slowed down the efficiency of the entire department.

Third, insurance companies work overtime seriously. Delays in getting off work hours and overtime on weekends are very common on site, resulting in a lack of rest time for employees. 9 out of 10 interviewees said that working hours are too long and work pressure is too high, which makes them feel tired and is difficult for them to balance work and life.

Fourth, compared with other industries, the salary of the insurance industry has a significant gap. 8 of the 10 interviewees expressed their dissatisfaction with their 
salary and believed that their salary was not equal to their contribution to the company. In addition, the salary gap between senior managers and ordinary employees is too large, causing some employees to be psychologically imbalanced, which leads to negative emotions.

In addition, employees are more satisfied with other aspects:

First, the company attaches great importance to the infrastructure, and a large-scale equipment update is carried out every 3 to 5 years to ensure the comfort of employees at work. All the 10 interviewees expressed their satisfaction with the infrastructure.

Second, the company's promotion mechanism is very reasonable. 8 of the 10 interviewees said they were very satisfied with their promotion space. The company's promotion mechanism far exceeded their career development plan for the next 3 to 5 years, which greatly enhanced their loyalty to the company.

Third, the company's training system is very complete, with dedicated training venues and a large number of online and offline courses to choose from. Employees can acquire all the necessary skills in the company's training courses. 9 out of 10 interviewees said that the training provided by the company was very comprehensive, which enabled them to get enough ability to cope with their work difficulties.

Fourth, the company has a very complete reward mechanism. It rewards employees for their outstanding contributions by providing certificates, public praise, and small home furnishings, which enables employees to gain a great sense of accomplishment in this job. 9 out of 10 interviewees expressed their satisfaction with their colleagues.

Fifth, the employee relationship is very harmonious. Good employee relations help each employee maintain a good working condition, thereby improving overall work efficiency. 9 out of 10 interviewees expressed their satisfaction with their colleagues.

Sixth, the relationship between superiors and superiors is very harmonious. All 10 interviewees said that the superiors and superiors get along well in this company, which helps them to work more easily.

In summary, the researchers made recommendations for the company from the following three aspects:

First, it is recommended that the company strengthen the promotion of corporate culture, increase public recognition of the company, and attract more young people to join the company, bringing enthusiasm and vitality to the company.

Second, improve the work efficiency of all employees, while adjusting the arrangement of work tasks to minimize the occurrence of overtime.
Third, salary is the most unsatisfactory factor for insurance company employees. It is recommended that the company adjust the company's salary structure and increase the overall salary of employees in a unified way to reduce the loss of core employees.

\section{CONCLUSION}

The purpose of this research is to explore the satisfaction of Chinese life insurance company employees with the company and the reasons for their retention, to help companies improve to meet the changing market environment, and to prepare for future brain drain. In order to achieve this broad goal, the researchers adopted semi-structured interviews to collect data from managers, employees, and insurance salespersons.

It can be found through interviews that the main problems faced by insurance companies are low employee motivation and low public acceptance. It can be seen from the data that salary is still the most important retention factor considered by employees. The salary that does not match the contribution and the huge income gap between different levels make employees feel frustrated, so employees' motivation to work is significantly reduced. In addition, high-intensity overtime is done by extending the working hours, which will lead to insufficient work energy, boredom of work, and a tendency to leave. The root cause of this phenomenon is that the overall work efficiency of employees still needs to be improved. The last but most important point is that the people's resistance to the insurance industry has greatly reduced the enthusiasm of the salespersons, resulting in a decrease in employees' recognition of the work. Insurance is the protection of people. People can get livelihood security when they encounter major diseases or unexpected accidents. However, due to some legacy social reasons, many people still disagree with the insurance industry, and even think that the promotion of insurance is a means of fraud. The insurance industry and society are mutually beneficial. Society diversifies risks because of the insurance industry, and the insurance industry develops rapidly because of market demand. Therefore, it is urgent to increase the public's recognition of the insurance industry.

The results of this research will help the insurance company to reasonably meet the needs of employees from multiple perspectives, improve employee career development plans and greatly increase employee satisfaction. This research has a small sample of interviews and a single data collection method. In future research, the researcher may increase the sample size and conduct investigations for several months or longer to explore the underlying reasons behind social problems. 


\section{REFERENCES}

[1] Cloutier, O., Felusiak, L., Hill, C., \& PembertonJones, E. J. (2015). The importance of developing strategies for employee retention. Journal of Leadership, Accountability \& Ethics, 12(2).

[2] Doh, J. P., Stumpf, S. A., \& Tymon, W. G. (2011). Responsible leadership helps retain talent in India. In Responsible leadership (pp. 85-100). Springer, Dordrecht.

[3] Herzberg, F., Mausner, B. and Snyderman, B., (1959) The Motivation to Work. New York: John Wiley and Sons, Inc.

[4] Hong, E. N. C., Hao, L. Z., Kumar, R., Ramendran, C., \& Kadiresan, V. (2012). An effectiveness of human resource management practices on employee retention in institute of higher learning: A regression analysis. International journal of business research and management, 3(2), 60-79.

[5] James, L., \& Mathew, L. (2012). Employee retention strategies: IT industry. SCMS Journal of Indian Management, 9(3), 79.

[6] Maslow, A. H. (1981). Motivation and personality. Prabhat Prakashan.

[7] McClelland, D. C., Atkinson, J. W., Clark, R. A., \& Lowell, E. L. (1953). The achievement motive. New York, 5.

[8] Schein, E. H. (1990). Organizational culture (Vol. 45, No. 2, p. 109). American Psychological Association.

[9] Scott, D., McMullen, T., \& Royal, M. (2012). Retention of key talent and the role of rewards. WorldatWork Journal, 21(4), 58-70. 